\title{
Beobachtungen der Helligkeit des Cometen 1899 a (Swift).
}

(Ergänzung und Fortsetzung zu Nr. 3574).

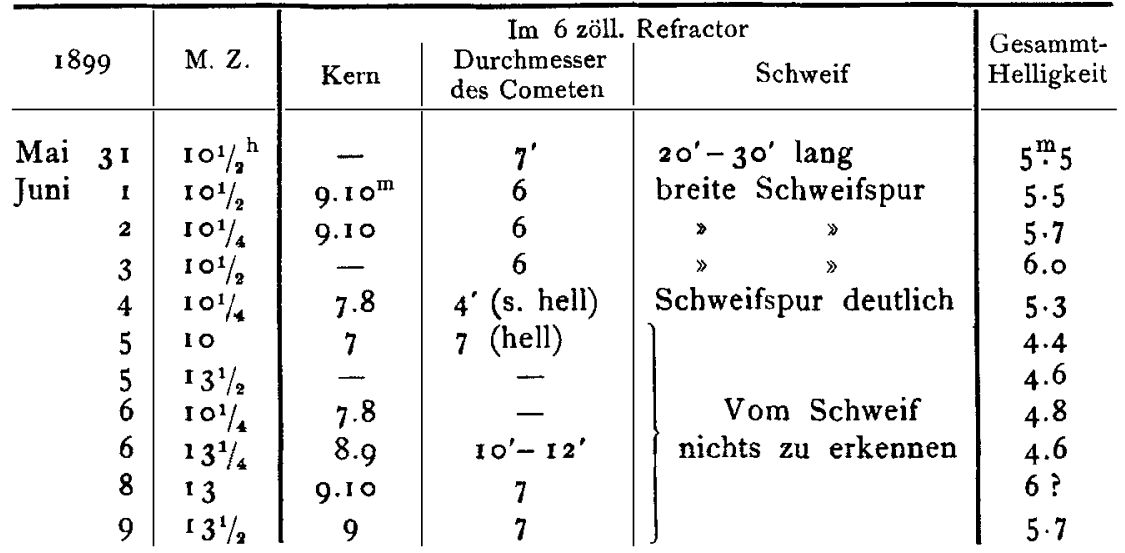

Wien, k. k. Sternwarte, 1899 Juni 10.

\section{F. Holetschek.}

\section{Wiederauffindung des Holmes'schen Cometen (1892 III) $1899 \mathrm{~d}$.}

Telegramm aus Boston, eingegangen Juni 12 früh.

-Keeler telegraphs: Comet Holmes was observed by Perrine June ro.9644 Gr.m.t. RA.app. $=18^{\circ} 52^{\prime} 54^{\prime \prime}$ PD. app. $=72^{\circ} 30^{\prime} 2 \mathrm{I}^{\prime \prime}$ faint. Pickering.*

Die mittlere der Zwiers'schen Ephemeriden in A. N. 3553 erfordert hiernach die Correction: - $22^{\mathbf{s} 2}$ in RA. und $-4^{\prime} 18^{\prime \prime}$ in Decl., entsprechend einer Correction der Perihelzeit von + 0.40 Tagen.

$K r$.

\section{Planet $1899 \mathrm{EN}=(85)$ Io.}

Der Planet 1899 EN, dessen tägliche Bewegung in Poldistanz nach einer Mittheilung von Prof. A. Abetti $-6^{\prime}$ statt $+4^{\prime}$ zu lesen ist, ist identisch mit dem von Herrn G. Witt vermissten Planeten (85) Io. Der Oppositionsort im Berl. Jahrb. I90I ist fehlerhaft; die Elemente geben, innerhalb der durch die Vernachlässigung der Störungen seit 1889 verursachten Unsicherheit, den Ort von EN genau wieder.

$K r$.

Anzeige. Der Unterzeichnete sucht einen jüngeren Astronomen für die neu zu besetzende Assistentenstelle an der astrophysikalischen Abtheilung der Grossh. Sternwarte Königstuhl bei Heidelberg. Max Wolf.

Abonnements - Anzeige. Die Herren Abonnenten, welche die Astronomischen Nachrichten ferner zu erhalten wünschen, werden ersucht, ihre Bestellung und Vorausbezahiung auf den folgenden Band baldmöglichst einzusenden, wofern es der Expedition nicht bekannt ist, dass sie als ständige Abonnenten angesehen werden wollen.

Man pränumerirt bei der Expedition der Astronomischen Nachrichten in Kiel, Niemannsweg ro3, mit I5 Mark für den Band von 24 Nummern nebst Inhaltsverzeichniss und Register.

Den buchhändlerischen Vertrieb besorgt die Firma W. Mauke Söhne in Hamburg.

Geschlossene Bände, von Band 33 an, können jederzeit von der Expedition in Kiel zum Preise von I 2 Mark pro Band bezogen werden. Bei Abnahme einer grösseren Reihe von Bänden tritt Preisermässigung ein, über welche in jedem besonderen Falle die Expedition Auskunft zu ertheilen bereit ist. Aeltere Bände als Band 33 sind, wenn überhaupt, nur noch in beschränkter Zahl vorhanden und können einzeln nicht mehr abgegeben werden.

Einzelne Nummern werden zur Completirung, wenn sie vorräthig sind, zum Preise von 60 Pfennig abgelassen.

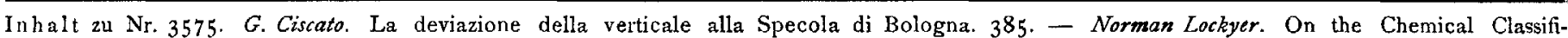
cation of the Stars. 387. - Anton Staus, Max Mïndler. Beobachtung der totalen Mondfinsterniss 1898 Dec. 27 . 391 . C. A. de Campos Rodrigues. Observations des Lénides 1898 . 393. - W. Doberck. Proper Motions of some southern stars. 395. - Torvald Kohl. Ueber die Perioden der Sterne S und T Ursae majoris. 397. - C. F. Merfield. Parabolic Elements of Comet 1899 a (Swift). 397. - E. Millosevich. Pianeta (389) [1894 BB]. 397. - F.Holetschek. Beobachtungen der Helligkeit des Cometen 1899 a (Swift). 399. - Wiederauffindung des Holmes'schen Cometen (I892 IIr) 1899 d. 399 . Planet $1899 \mathrm{EN}=(85)$ Io. 399. - M. Wolf. Anzeige. 399. - Abonnements-Anzeige. 399. 